\title{
Real world long-term impact of intensive treatment on disease activity, disability and health-related quality of life in rheumatoid arthritis
}

Nicola J. Gullick ${ }^{1 *}$, Fowzia Ibrahim², lan C. Scott ${ }^{3,4,6}$, Alexandra Vincent ${ }^{5}$, Andrew P. Cope ${ }^{5,6}$, Toby Garrood ${ }^{5}$, Gabriel S. Panayi ${ }^{5}$, David L. Scott ${ }^{2}$, Bruce W. Kirkham ${ }^{5}$ and On behalf of TITRATE Programme Investigators

\begin{abstract}
Background: The emphasis on treating rheumatoid arthritis (RA) intensively reduces disease activity but its impact in routine care is uncertain. We evaluated temporal changes in disease activities and outcomes in a 10-year prospective observational cohort study of patients in routine care at one unit.
\end{abstract}

Methods: The Guy's and St Thomas' RA cohort was established in 2005. It involved most RA patients managed in this hospital. Clinical diagnoses of RA were made by rheumatologists. Patients were seen regularly in routine care. Each visit included measurement of disease activity scores for 28 joints (DAS28), health assessment questionnaire scores (HAQ) and EuroQol scores. Patients received intensive treatments targeting DAS28 remission.

Results: In 1693 RA patients mean DAS28 scores fell from 2005 to 15 by 11\% from 4.08 (95\% Cl: 3.91, 4.25) in 2005 to 3. $64(3.34,3.78)$; these falls were highly significant $(p<0.001)$. DAS28 components: swollen joint counts fell by $32 \%$ and ESR by 24\%; in contrast tender joint counts and patient global assessments showed minimal or no reductions. The reduction in DAS28 scores was predominantly between 2005 and 2010, with no falls from 2011 onwards. Associated with falls in mean DAS28s, patients achieving remission increased (18\% in 2005; $27 \%$ in 2015) and the number with active disease (DAS28 > 5.1) decreased (25\% in 2005; 16\% in 2015). In 752 patients seen at least annually for 3 years, persisting remission (68 patients) and intermittent remission (376 patients) were associated with less disability and better health related quality of life. Over time biologic use increased, but they were used infrequently in patients in persistent remission.

Conclusions: Over 10 years an intensive management strategy in a routine practice setting increased combination DMARD and biologic use: disease activity levels declined; this association is in keeping with a causal relationship. Patients who achieved remission, even transiently, had better functional outcomes than patients never achieving remission.

Keywords: Temporal RA change, Intensive treatment, Rheumatoid arthritis

\section{Background}

In recent years the management of rheumatoid arthritis (RA) has been transformed. Methotrexate is used earlier, access to biologics has increased, and effective combinations of conventional disease modifying anti-rheumatic drugs (DMARDs) have been identified. National and international guidelines highlight the value of using these

\footnotetext{
* Correspondence: Nicola.Gullick@uhcw.nhs.uk

${ }^{1}$ Department of Rheumatology, University Hospitals Coventry and Warwickshire NHS Trust, Coventry, UK

Full list of author information is available at the end of the article
}

approaches in early, intensive and effective treatment [1-4]. The treat to target initiative has provided additional support $[5,6]$. The overall impact of these innovations on patient outcomes in routine care settings remains uncertain.

Over 30 years ago, Silman and colleagues [7] suggested RA severity was declining. Many groups subsequently reported temporal improvements in RA. Some focussed on disease activity in early RA [8-12]; others concentrated on disease activity in established RA [13-17]. A few assessed erosive damage $[18,19]$ and joint replacement surgery [20,21]. All studies provide some evidence

(c) The Author(s). 2019 Open Access This article is distributed under the terms of the Creative Commons Attribution 4.0 International License (http://creativecommons.org/licenses/by/4.0/), which permits unrestricted use, distribution, and reproduction in any medium, provided you give appropriate credit to the original author(s) and the source, provide a link to the Creative Commons license, and indicate if changes were made. The Creative Commons Public Domain Dedication waiver (http://creativecommons.org/publicdomain/zero/1.0/) applies to the data made available in this article, unless otherwise stated. 
of temporal improvements in RA outcomes. Such improvements could reflect treatment innovations and implementation of guidelines recommendations. Other potential influences include earlier referral resulting in more patients receiving effective therapy during the initial "window of opportunity" [22], changes in the clinical phenotype of RA [23] and changes in the relationship of RA to comorbid conditions [24].

More information is needed on the benefits of implementing intensive treatment strategies in routine clinics and the potential for further improvements. We examined both questions in a single-centre prospective observational study which recorded changes in disease activity, disability and health related quality of life (HRQoL) in patients managed intensively between 2005 and 2015.

\section{Methods}

\section{Patients}

Patients attending the Guy's and St Thomas' NHS Trust RA Centre formed a prospective longitudinal observational cohort study [25]. The majority of RA patients managed at this hospital were included. All patients had clinical diagnoses of RA made by experienced rheumatologists. They were seen regularly for routine care and each visit involved a clinical review and assessment of key clinical outcomes. Management followed the treat to target approach with an aim of reaching DAS28 remission defined as DAS28 $<2.6[5,25]$. The patients were analysed in two ways: firstly, all patients in whom data was available; secondly, patients who were followed for three years or more. Details were collected about age, disease duration, sex and ethnicity.

\section{Treatments}

Patients received treatment with DMARDs and biologics in line with existing English guidance about these treatments using a goal-directed strategy [26]. They received intensive DMARDs, often given in combination, and also had biologics when they met the existing guidelines from the National Institute for Health and Care Excellence (NICE). These English guidelines have changed over time and the approach taken reflected the guidance existing at the time treatment decisions were made and guidance from EULAR about treat to target $[5,27]$.

\section{Outcomes}

The disease activity score 28 (DAS28), incorporating swollen and tender joint counts, patient's global assessments, and erythrocyte sedimentation rates (ESR) evaluated patients' current status [28], and was used to guide treatment decisions. The Heath Assessment Questionnaire (HAQ) measured disability [29]. The
EuroQol 5-dimension scale (EQ5D-3 L) measures health-related quality of life [30]; it can be used to estimate health utility and has been widely used in RA. Flares were also assessed as changes between DAS28 assessments in which there was an increase in score of 0.60 or more [31].

\section{Data collection}

Data were captured in the electronic healthcare records for inflammatory arthritis patients attending outpatient clinics at Guy's and St Thomas' Hospital NHS Foundation Trust (GSST). These records are within the Trust's Electronic Patient Records system which provides laboratory results and patient demographics. Clinical data on a patient's treatment, disease activity, disability level, and health-related quality of life (HRQoL) were routinely captured at their clinic appointment and were used for patients' routine care.

\section{Analyses}

Data management and analyses used Stata (version 14.0, StataCorp, College Station, TX). Descriptive analyses used numbers of patients and percentages and mean scores with standard deviations or $95 \%$ confidence intervals (CI). We used mixed models to examine the changes in DAS28 and its components over time. We also used trend analysis to take into account repeated measures from the same patient. Subgroups were compared by Chi-Squared analyses or by one-way analysis of variance.

\section{Ethics approval}

Ethics approval for analysis of this routine clinical data was obtained from the Health Research Authority (IRAS project ID: 209418).

\section{Results \\ Patients studied \\ All patients}

Between 2005 and 20151693 RA patients were entered into the database. Most were female (1262, 75\%) and Caucasian (1134,67\%). Their mean age was 55 years and mean disease duration was 11 years. The median time between assessments was 3 (IQR: 2-6) months and the mean was 5.3 (SD 6.6) months. Details of the patients are shown in Table 1. Numbers of patients with data in each calendar year are shown in Additional file 1: Table S1. Out of the total sample 337/1693 (19\%) had at least one missing DAS28 during follow up. Similar proportions of HAQ and EQ5D data were missing (22 and 20\% respectively). 
Table 1 Baseline Characteristics Of Patients Studied: Number (\%) or Mean (SD) Values Are Shown

\begin{tabular}{|c|c|c|c|c|}
\hline & & $\begin{array}{l}\text { All } \\
\text { Patients }\end{array}$ & $\begin{array}{l}\text { Patients Followed Over Three Or More } \\
\text { Years }\end{array}$ & $\begin{array}{l}\text { Patients Followed Less Than Three } \\
\text { Years }\end{array}$ \\
\hline & & $(n=1693)$ & $(n=752)$ & $(n=941)$ \\
\hline \multirow[t]{3}{*}{ Gender, n (\%) } & Female & $\begin{array}{l}1262 \\
(75 \%)\end{array}$ & $579(77 \%)$ & $683(73 \%)$ \\
\hline & Male & $412(24 \%)$ & $165(22 \%)$ & $247(26 \%)$ \\
\hline & Missing & $19(1 \%)$ & $8(1 \%)$ & $11(1 \%)$ \\
\hline \multirow[t]{5}{*}{ Ethnicity, n (\%) } & Caucasian & $\begin{array}{l}1134 \\
(67 \%)\end{array}$ & $540(72 \%)$ & $594(63 \%)$ \\
\hline & $\begin{array}{l}\text { Black African/ } \\
\text { Caribbean }\end{array}$ & $209(12 \%)$ & $100(13 \%)$ & 109 (11\%) \\
\hline & $\begin{array}{l}\text { Asian/other } \\
\text { background }\end{array}$ & $128(8 \%)$ & $52(7 \%)$ & $76(8 \%)$ \\
\hline & Not Stated & $79(5 \%)$ & $27(4 \%)$ & $52(6 \%)$ \\
\hline & Missing & $143(8 \%)$ & $33(4 \%)$ & $110(12 \%)$ \\
\hline Age (years) & & $55(16)$ & $55(15)$ & $55(14.7)$ \\
\hline Disease Duration (years) & & $11(10)$ & $10(10)$ & $10(9.7)$ \\
\hline Tender Joint Counts (28 joints) & & $5.0(6.6)$ & $4.8(6.0)$ & $5.2(6.5)$ \\
\hline Swollen joint Counts (28 joints) & & $2.9(4.7)$ & $3.2(3.9)$ & $3.3(4.3)$ \\
\hline $\begin{array}{l}\text { Erythrocyte Sedimentation Rate } \\
(\mathrm{mm} / \mathrm{hr})\end{array}$ & & $22(21)$ & $22(21)$ & $21.5(22)$ \\
\hline Patient Global Assessment (mm) & & $46(28)$ & $44(27)$ & $45(28)$ \\
\hline DAS28 & & $\begin{array}{l}3.83 \\
(1.63)\end{array}$ & $3.79(1.50)$ & $3.85(1.62)$ \\
\hline Health Assessment Questionnaire & & $\begin{array}{l}1.18 \\
(0.83)\end{array}$ & $1.22(0.86)$ & $1.18(0.83)$ \\
\hline EQ5D-3 L & & $\begin{array}{l}0.53 \\
(0.34)\end{array}$ & $0.52(0.33)$ & $0.53(0.34)$ \\
\hline
\end{tabular}

\section{Patients followed over three or more years}

Seven hundred fifty-two patients were seen at least annually over three years or more. Their baseline features were similar to those of the overall group (Table 1). The median time between assessments was 3.5 (IQR 1-5) months and mean was 5.0 (SD: 5.5) months.

\section{Changes in DAS28 \\ All patients}

There were 10,773 measures of DAS28 in the 1693 patients. DAS28 scores fell when assessed as mean changes by calendar years (Fig. 1). The mean DAS28 scores fell by $11 \%$ from 4.08 (95\% CI: 3.91, 4.25) in 2005 to $3.64(3.34,3.78)$ in 2015 . A mixed effects maximum likelihood regression model showed the coefficient was $-0.033(95 \%$ CI $-0.044,-0.023)$ and these falls in DAS28 were highly significant $(p<$ 0.001 ). The reduction in DAS28 scores was predominantly between 2005 and 2010; there were no falls from 2011 onwards. Associated with these falls in mean DAS28 scores was an increase in the number of patients in remission (18\% in $2005 ; 27 \%$ in 2015) and the number with active disease (DAS28 > 5.1) decreased $(25 \%$ in $2005 ; 16 \%$ in 2015$)$.

\section{Patients followed over three or more years}

There were 4345 annual measures of DAS28 in the 752 patients with at least three annual clinic visits. Their mean DAS28 scores showed similar falls over time (Fig. 1). The mean DAS28 scores fell $12 \%$ from 3.95 (95\% CI 3.73, 4.17) to 3.48 (95\% CI 3.22, 3.74). Trend analysis, which takes into account repeated measures, showed similar changes (Additional file 2: Table S2). The number of patients in remission also increased (20\% in $2005 ; 29 \%$ in 2015$)$ and the number with active disease decreased (21\% in $2005 ; 14 \%$ in 2015$)$.

\section{Changes in DAS28 components All patients}

Changes in the components of DAS28 showed varied patterns of change over time in all patients (Fig. 2). Swollen joint counts fell by $32 \%$ from 3.1 (95\% CI 2.7, 3.5) in 2005 to $2.1(95 \%$ CI $1.7,2.5)$ in 2015 . The ESR showed similar 

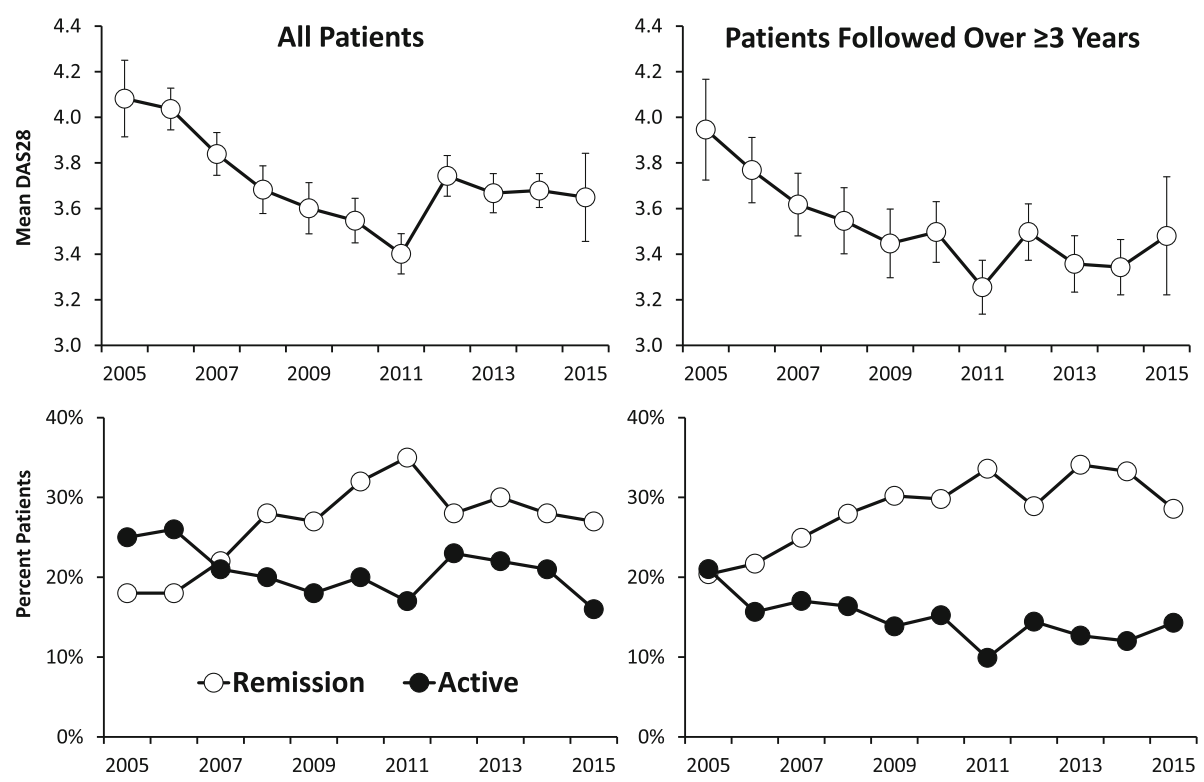

Fig. 1 Changes in DAS28 (Means with 95\% Confidence Intervals) and Percent Patients in Remission and with Active Disease

falls of $24 \%$ from 25 (95\% CI 22, 27) in 2005 to 19 (95\% CI $16,20)$ in 2005 . In contrast tender joint counts fell by only $10 \%$ from 5.0 (95\% CI 4.4, 5.7) to $4.5(95 \%$ CI $3.7,5.2)$ and patient global assessments increased by $9 \%$ from $43(95 \%$ CI 40,46$)$ to $47(95 \%$ CI 44,50$)$.

\section{Patients followed over three or more years}

These patients showed a similar pattern of change (results not shown). Swollen joint counts fell by $49 \%$, ESR by $25 \%$ and tender joint counts by $17 \%$; but patient global increased by $8 \%$.
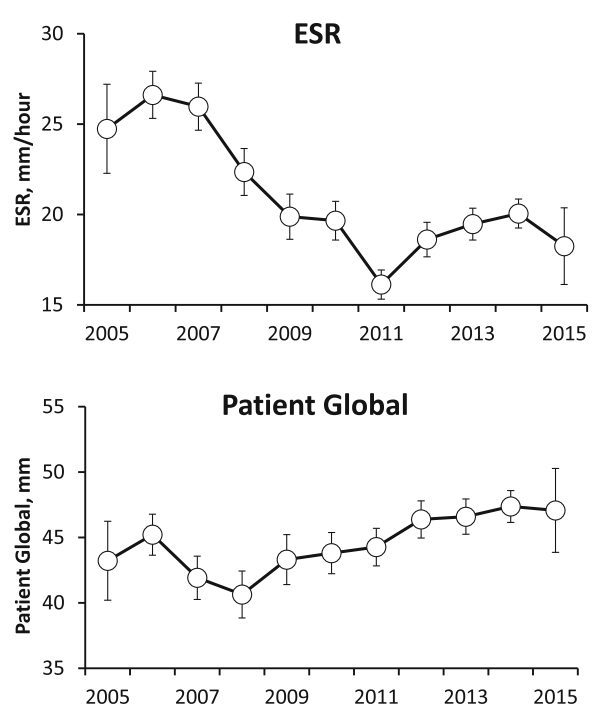

Remission status in patients followed over three or more years

Disease activity groups and remission status

Based on the presence of remission the patients were subdivided into 3 sub-groups: 68 (9\%) were always in remission, $376(50 \%)$ had one or more episodes of remission without being sustained, and 308 never achieved remission. There were substantial differences between these groups (Table 2). In addition $16 \%$ had sustained low disease activity or remission and $58 \%$ had point low disease activity or remission at one or more time-points without being sustained.
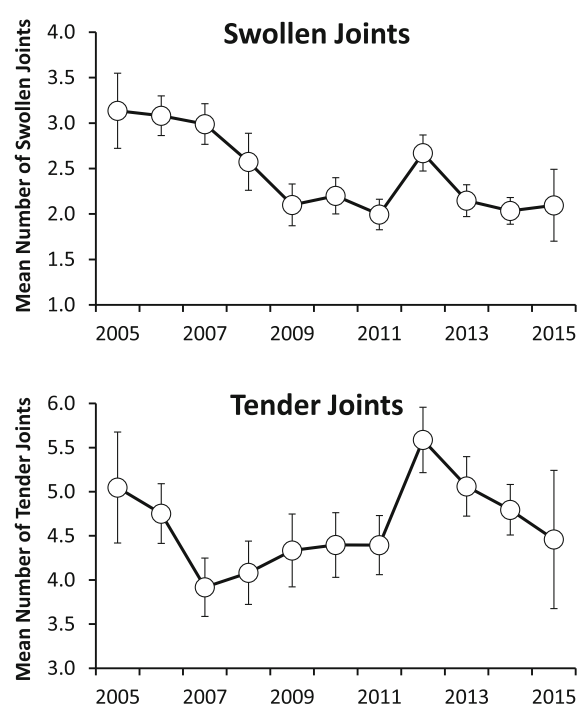

Fig. 2 Changes in Components of DAS28 in All Patients (Mean With 95\% Confidence Intervals) 
In the relatively small group of 68 patients always in remission, there were fewer females (50\%), more patients with Caucasian ethnicity (85\%) and shorter mean initial disease duration (5 years). The other two groups had similar numbers of females (80\%) and similar initial disease durations (10 and 12 years). Patients with intermittent remission included more patients with Caucasian ethnicity (76\%) and fewer with Black African/Caribbean Ethnicity (10\%) than those without remission (63 and $20 \%$ respectively).

By definition overall mean DAS28 scores were lowest in those patients who were always in remission and highest in patients with no remission. Flares (increase in DAS2 $\geq 0.6$ between consecutive assessments) occurred in $40 \%$ of patients always in remission and 71 and $63 \%$ of the other patient groups. Overall mean EQ5D-3 L scores were highest (better) in patients always in remission and lowest in patients with no remission.

Patients who never achieved remission included 14 patients who always had high disease activity (DAS28 > 5.1). All 14 patients were females with longer initial disease durations (17 years); only 8 (57\%) had Caucasian ethnicity. They had very low overall mean EQ5D-3 L scores (0.07).

\section{Changes in DAS28 scores and remission status}

The 3 subgroups showed differences in DAS28 scores from 2005 to 2015 (Fig. 3). There were no temporal changes in patients always in remission and patients who never had remission. By contrast in patients with one or more remissions, DAS28 scores fell by $25 \%$ from 3.75 (95\% CI 3.46, $4.03)$ to 2.80 (95\% CI 2.54, 3.07).

\section{Changes in treatment and remission status}

The use of DMARD monotherapies, combination DMARDs and biologics changed over time (Fig. 4). Initially $55 \%$ of patients were taking DMARD monotherapies and 19\% biologics. DMARD monotherapy fell progressively, with increasing use of biologic therapies; by 2015 this had changed to $35 \%$ of patients taking DMARD monotherapies and $42 \%$ biologics. Similar changes in biologics use were seen in patients followed over three or more years (Additional file 3: Table S3).

Patients always in remission received fewer DMARD monotherapies and biologics compared to patients with some or no remissions. There was strong evidence of increasing intensity of care in line with the intensive treatment strategy; in particular patients with initial moderate disease had increased biologic use rising from under one quarter in 2005 to over one half by 2015 irrespective of remission status (Additional file 4: Figure S2).

\section{Disability and remission status}

Overall mean HAQ scores were lowest in the patients always in remission. $85 \%$ of these patients had HAQ scores below 0.50 on one or more occasions. Overall mean HAQ scores were highest in patients with no remissions and only $18 \%$ had HAQ scores below 0.50 on one or more occasions.

In all three subgroups there was a relationship between low HAQ scores and low patient global scores (Fig. 5). This analysis shows that irrespective of remission status, those patients who had overall mean patient global scores under 30 were significantly more likely to have HAQ scores below 0.5, regardless of their remission status. This difference was significant in all three

Table 2 Disease Activity Sub-Groups In Patients Followed Over Three Or More Years

\begin{tabular}{|c|c|c|c|c|}
\hline & $\begin{array}{l}\text { Always Remission } \\
(n=68)\end{array}$ & $\begin{array}{l}\text { Some Remission } \\
(n=376)\end{array}$ & $\begin{array}{l}\text { No Remission } \\
(n=308)\end{array}$ & Significance \\
\hline Females (\%) & $34(50 \%)$ & $299(80 \%)$ & $246(80 \%)$ & $P<0.001^{*}$ \\
\hline Caucasian Ethnicity (\%) & $58(85 \%)$ & $287(76 \%)$ & $195(63 \%)$ & $P<0.001^{*}$ \\
\hline Black African/Caribbean Ethnicity (\%) & $1(2 \%)$ & $37(10 \%)$ & $62(20 \%)$ & $P<0.001^{*}$ \\
\hline Initial Mean Age In Years (SD) & $54(16)$ & $55(15)$ & $56(14)$ & $N S^{* *}$ \\
\hline Initial Disease Duration In Years (SD) & $5(5)$ & $10(9)$ & $12(11)$ & $P=0.003^{* *}$ \\
\hline Initial Mean DAS28 (SD) & $1.65(0.65)$ & $3.48(1.32)$ & $4.65(1.19)$ & $P<0.001^{* *}$ \\
\hline Overall Mean DAS28 (SD) & $1.57(0.45)$ & $3.06(0.71)$ & $4.47(0.82)$ & $P<0.001^{* *}$ \\
\hline Any Flares (\%) & $27(40 \%)$ & $266(71 \%)$ & $194(63 \%)$ & $P<0.001^{*}$ \\
\hline Overall Mean EQ5D-3 L (SD) & $0.77(0.17)$ & $0.58(0.24)$ & $0.38(0.28)$ & $P<0.001^{* *}$ \\
\hline Initial Mean HAQ (SD) & $0.31(0.50)$ & $1.06(0.81)$ & $1.58(0.81)$ & $P<0.001^{* *}$ \\
\hline Overall Mean HAQ (SD) & $0.31(0.45)$ & $1.03(0.70)$ & $1.66(0.67)$ & $P<0.001^{* *}$ \\
\hline HAQ Below 0.50 On One Or More Occasion (\%) & $58(85 \%)$ & $180(48 \%)$ & $56(18 \%)$ & $P<0.001^{*}$ \\
\hline
\end{tabular}

*Chi-Squared Testing **One Way Analysis Of Variance 


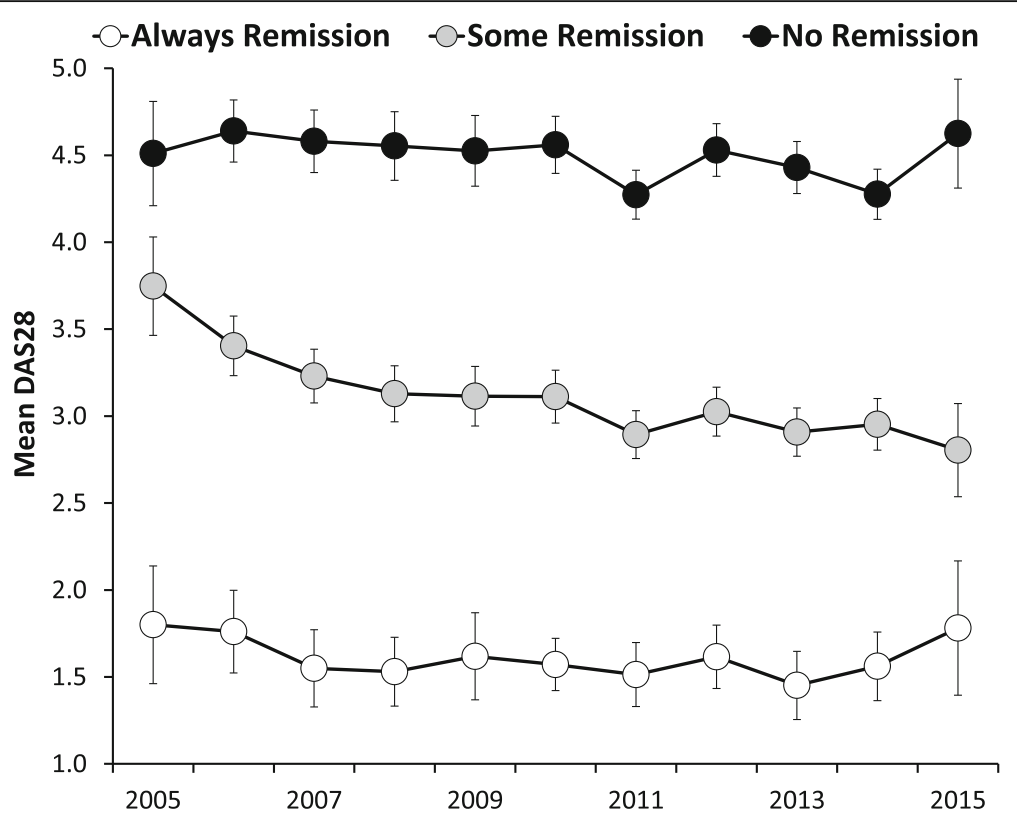

Fig. 3 Changes in DAS28 in Three Sub-Groups of Patients Followed Over Three or More Years

subgroups (Chi Squared analyses showed that in patients always in remission the significance level of the difference was 0.013; in both other groups it was $<0.001$ ).

Finally in the subgroup with some remission, 62/110 $(56 \%)$ who had no flares (increase in DAS28 $\geq 0.60$ ) had one or more HAQ scores $<0.5$ compared with $118 / 266$ (44\%) of patients who had one or more flares. This difference was significant (Chi-Squared with continuity correction 4.02; DF $1 ; p=0.034$ ). Flares were unrelated to low HAQ scores in the other remission groups.

\section{Impact of flares}

Patients who had more flares had overall higher mean HAQ scores and higher end-point HAQ scores (Table 3).
When patients who were always in remission were excluded, the end-point HAQ remained significantly different between remission groups $(P=0.043$ on one way analysis of variance) but the overall mean HAQ was no longer significantly different.

\section{Impact of disease duration}

Dividing patients followed for three years or more into those with disease durations of less than 5 years and those with more than 5 years showed no evidence that DAS28 scores were different over time between them (Additional file 5: Figure S1) However, there two differences between them (a) sustained remission was more frequently seen in patients with less than 5 years duration (12\% versus $3 \%$; Chi-squared

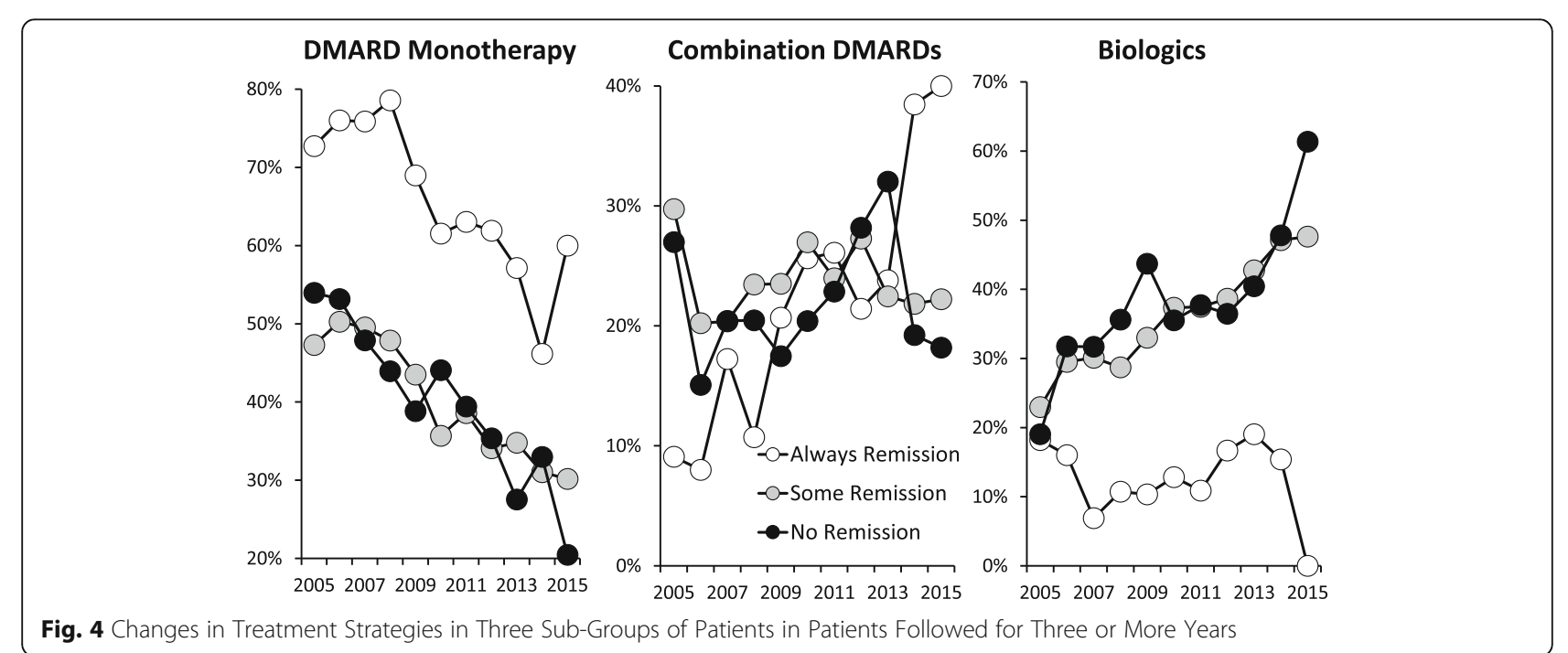




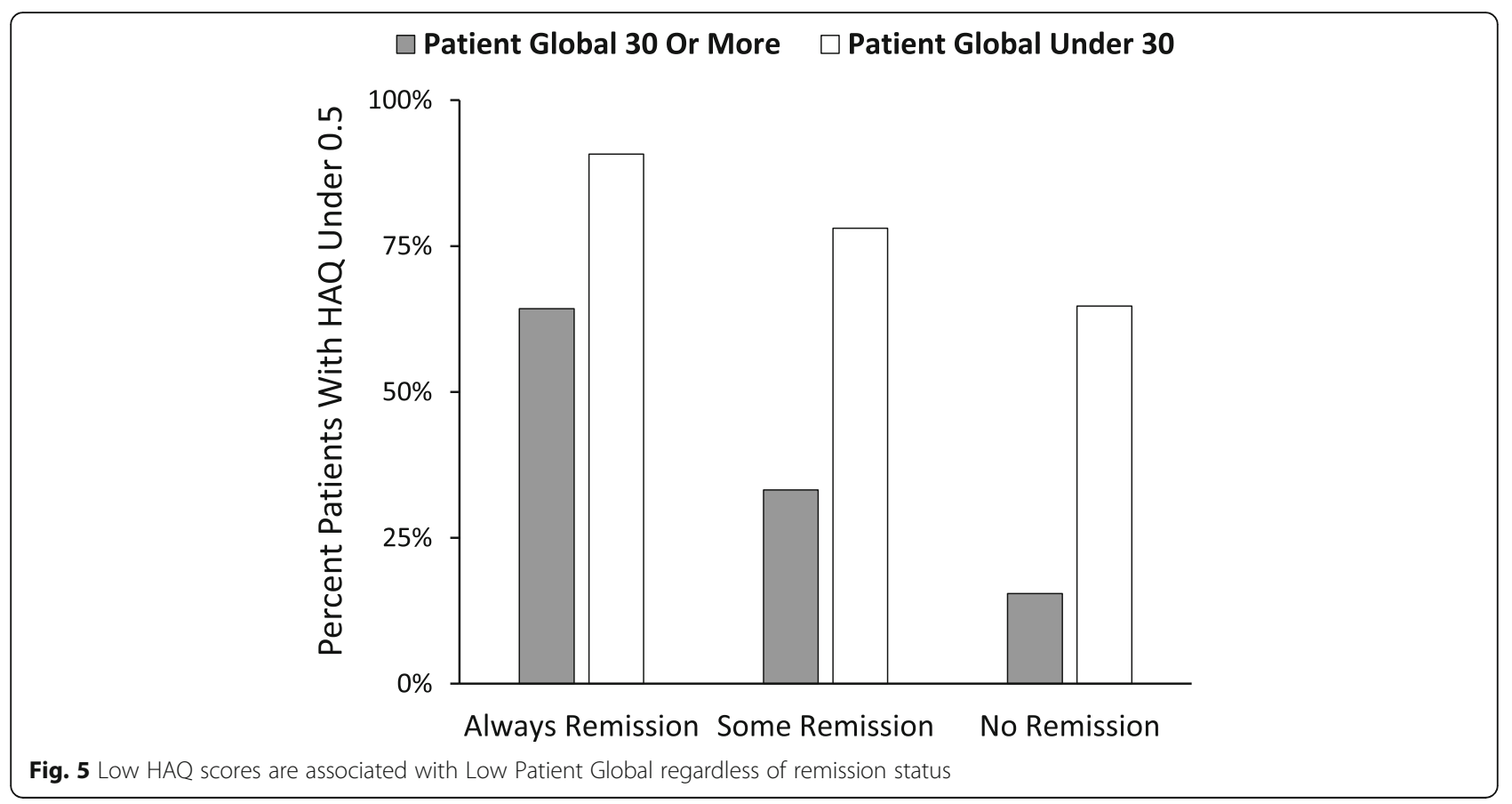

10.8 ; $D F=1 ; P=0.001$ ); (b) flares were more frequently seen in patients with more than 5 years duration $(78 \%$ versus $62 \%$; Chi-squared 11.9; $\mathrm{DF}=1 ; P=0.001)$.

\section{Discussion}

Our long-term real world observational study shows both the potential benefits and limitations of a goal directed, intensive treatment strategy for patients with established RA. A preliminary cross sectional analysis of goal directed therapy in these patients compared to a matched group receiving less intensive approaches has previously established the benefit of this approach [25].

During the decade of follow-up reported here, treatment intensities increased, mean disease activity fell and there were more remissions. Patients who achieved one or more remissions had lower levels of disability and higher health related quality of life. However, not all patients responded to intensive treatment and a small

Table 3 Relationship Between Flares And Disability

\begin{tabular}{llll}
\hline $\begin{array}{l}\text { Number of } \\
\text { Flares }\end{array}$ & Number Of Patients & $\begin{array}{l}\text { Overall HAQ } \\
\text { Mean }(95 \% \mathrm{Cl})\end{array}$ & $\begin{array}{l}\text { Final HAQ } \\
\text { Mean }(95 \% \mathrm{Cl})\end{array}$ \\
\hline 0 & 260 & $1.08(0.98,1.18)$ & $1.19(1.08,1.31)$ \\
1 & 290 & $1.29(1.20,1.38)$ & $1.23(1.13,1.33)$ \\
2 & 127 & $1.21(1.08,1.35)$ & $1.32(1.16,1.48)$ \\
3 & 47 & $1.50(1.33,1.66)$ & $1.53(1.28,1.78)$ \\
4 & 14 & $1.43(1.11,1.75)$ & $1.73(1.27,2.20)$ \\
One Way & & $P=0.002$ & $P=0.029$ \\
$\begin{array}{l}\text { Analysis Of } \\
\text { Variance }\end{array}$ & & & \\
\hline
\end{tabular}

minority had persistently active disease with high disability levels and low health related quality of life.

The presence of intermittent and persistent remissions had a substantial relationship with both treatment and disease outcomes. Patients with remissions were more likely to be male and Caucasian with shorter disease duration, which reflects previous experience predicting RA outcomes [32-34]. There were also differences in treatment intensity with patients in persisting remission having less intensive treatment and, in particular, fewer biologics. It is possible patients in sustained remission had any biologic treatment tapered and stopped.

Reduced DAS28 scores over time were only seen in those patients who had intermittent remission. In addition, we found strong relationships between disease activity, disability and health related quality of life. Patients with persistent remissions had the lowest HAQ and highest (best) EQ5D scores and patients who never had a remission had the highest HAQ and lowest EQ5D scores. An extensive body of clinical evidence from observational studies has previously highlighted these relationships, including reports from Alemo et al. [35] and Radner et al. [36, 37]. There is also evidence that with conventional non-intensive treatment, disability increased with disease duration and over time relationships between disease activity and disability change [38]. These findings highlight the importance for patients of controlling active disease. Overall in our patients DAS28 remission frequencies increased from an average of $18 \%$ in 2005 to $27 \%$ in 2015 in our patients. These remission rates are similar to those 
reported in trials of biologics in established RA. For example, Kivitz et al. [39] reported 32\% remission rates adding tocilizumab to methotrexate and Smolen et al. reported $23 \%$ remission rates adding certolizumab to methotrexate in established RA [40]. The DAS28 remission rates were relatively static in a long-term extension study [41].

The decreases in disease activity we observed over time reflect the previous evidence that RA is becoming less severe over time [7-21]. Interestingly we found that some aspects of disease activity, in particular swollen joint counts and the ESR, improved more than others, in particular patient's global assessments. We also noted patient global assessments were most closely associated with disability scores, reflecting our previous findings in clinical trials [42]. This is of potential clinical importance as it implies need for treatment of aspects of RA beyond inflammatory synovitis to reduce patient global assessments and improve disability in all patient groups. Long-term assessments from the BARFOT study have shown that whilst disease activity has declined over time, disability and pain have not [43]. One explanation for this finding is that some features of RA are not directly driven by synovial inflammation; and may represent "fibromyalgic RA" [44]. Such patients have more pain [45], often fail to achieve remission when treated intensively [46] and have less evidence of active synovitis [47]. It is possible that other drug treatments or non-drug treatments such as psychological support [48] or exercise [49] may be beneficial in these patients. The implication is that intensive drug treatment alone is not sufficient and the use of other approaches to manage established RA needs to be extended. It is also possible there is a lower level of DAS28 which can be achieved by current drug treatments as international comparisons in the QUEST-RA study found no country achieved mean DAS28 scores below 3.0 [50]. In addition the timing of NICE and other guidance may have influenced clinical practice, though we have not found any definite evidence to support this contention. The main strength of our study is that it presents findings from a single centre in which clinical staff followed an agreed management approach for RA based on goal-directed, intensive management approaches and used standardised clinical assessments. It also has several limitations. The principal weakness, inherent in all observational studies, is that we recruited consecutive patients irrespective of their disease severity or activity. It is therefore difficult to be certain how much secular trends in the severity of RA have contributed towards our findings, though recent analysis of early RA patients from England since 1990 does not suggest this has occurred to any great extent [24]. A second limitation is that patients were seen as required rather than in any standardised manner, reflecting current clinical practice. As patients with active disease are likely to be seen more frequently than patients in remission, this approach may over-estimate the relative frequency of active disease, particularly in the final years of the study. A third limitation is that patients were not followed-up if they left the clinic, which is in line with routine clinical practice. Consequently we cannot exclude impacts from censoring or informativeness of the follow-up process. A fourth limitation is that our treatments with biologics were influenced by NICE criteria; greater use of biologics might have improved outcomes even more. A fifth limitation is the definition of flares; other definitions were all developed some time after our study started and are difficult to apply retrospectively. A sixth limitation is that many patients did not remain under follow-up for over three years. The reasons for this are likely to be complex; death is one factor; London has a highly mobile population and patients frequently move within London or outside the capital; RA patients often have comorbid diseases and these can result in their moving to other hospitals for their care; and patients may stop attending specialist units, with historical studies suggest nearly half of RA patients may not be under specialist care receiving DMARDs during the course of their disease [51, 52] Finally, our cohort predominantly included patients with established disease rather than new referrals with early RA. Whilst this most closely reflects routine practice, it means caution must be used when comparing our findings with those from inception cohorts of early RA patients, which will include patients with mild disease who may not require follow up in specialist clinics.

\section{Conclusions}

We conclude intensive management regimens have been associated with progressive improvement in disease activity and more remissions over the last $10-15$ years. When patients achieve intermittent or sustained remission their function and quality of life improve. Our treat-to-target, goal-directed therapy strategy, using DAS28 as the measure, was used as a guide to medical therapy, with reductions in swollen joint count and ESR. Although we did not assess longitudinal radiographs in our population, it is likely that improvement in these disease attributes, also noted in other populations, most likely accounts for the substantial reduction in radiographic progression now seen in people with RA [53]. This is a significant achievement, as progressive joint damage was previously common in RA. However, tender joint counts and patient global assessments have improved less and may need alternative or additional treatment approaches. A minority of patients have continued high disease activity with substantial disability and reduced quality of life. Individualised 
strategies may be required for this group including novel therapies or psychological interventions.

\section{Additional files}

Additional file 1: Table S1. Patients seen in each calendar year (DOCX $36 \mathrm{~kb}$ )

Additional file 2: Table S2. Changes In DAS28 In Patients Followed For Three Or More Years Using Trend Analysis To Take Into Account Repeated Measures (DOCX 43 kb)

Additional file 3: Table S3. Treatments Used Over Time (DOCX 56 kb)

Additional file 4: Figure S2. Biologic Use In Patients With Initial Moderate Disease Activity And Remission Status (DOC 66 kb)

Additional file 5: Figure S1. Changes In Mean DAS28 Over Time In Patients Seen Within Five Years Of RA Onset Or Later (DOC 66 kb)

\section{Acknowledgements}

We acknowledge support from the NIHR Biomedical Research Centre at Guy's and St Thomas' NHS Foundation Trust in partnership with King's

College London.

On behalf of TITRATE Programme Investigators.

Work Stream A: Heidi Lempp, Jackie Sturt, Sofia Georgopoulou and Louise Prothero;

Work Stream B: Naomi Martin, Richard Jenner, Isabel Neatrour, Rhiannon Baggott, Fowzia Ibrahim, Brian Tom, Allan Wailoo, Jonathan Tosh, James Galloway, Gabrielle Kingsley and David Scott:

Work Stream C: Brian Tom, Fowzia Ibrahim, Yujie Zhong, Aneela Mian, James Galloway \& David L Scott.

\section{Funding}

The paper presents independent research funded by the National Institute for Health Research (NIHR) as one of its Programme Grants For Applied Research (Grant Reference Number: RP-PG-0610-10066; Programme Title: Treatment Intensities and Targets in Rheumatoid Arthritis Therapy: Integrating Patients' And Clinicians' Views - The TITRATE Programme). The views expressed are those of the authors and not necessarily those of the NHS, the NIHR or the Department of Health and Social care. Additional funding was received from Abbvie as a partnership project supporting analysis of RA Centre data. Dr. Nicola Gullick and Dr. Ian Scott were supported by NIHR Clinical Lectureships.

\section{Availability of data and materials}

The dataset used for this manuscript is kept at Guy's \& St Thomas' Hospitals (Dr Bruce Kirkham). The dataset is not publicly available to protect study participants' confidentiality. Ethical approval to share the study data with third parties has not been obtained.

\section{Authors' contributions}

NJG, DLS, GSP and BK conceived the study. NJG, AV, APC, TG, GSP, and BK collected the data. FI and ICS analyzed the data. NG, FI, DLS and BK wrote the manuscript. All authors read and approved the final manuscript.

\section{Ethics approval and consent to participate}

Ethics approval for analysis of routine clinical data was obtained from the Health Research Authority (IRAS project ID: 209418). The need for consent was waived due to the use of of previously collected, de-identified data, and complies with the Helsinki Declaration.

\section{Consent for publication}

Not applicable.

\section{Competing interests}

The authors declare that they have no competing interests.

\section{Publisher's Note}

Springer Nature remains neutral with regard to jurisdictional claims in published maps and institutional affiliations.

\section{Author details}

'Department of Rheumatology, University Hospitals Coventry and Warwickshire NHS Trust, Coventry, UK. ²Department of Rheumatology, 3rd Floor, Weston Education Centre, King's College London, Cutcombe Road, London, UK. ${ }^{3}$ Research Institute for Primary Care \& Health Sciences, Primary Care Sciences, Keele University, Keele, Staffordshire, UK. ${ }^{4}$ Department of Rheumatology, Haywood Hospital, High Lane, Burslem, Staffordshire, UK. 5Department of Rheumatology, Guy's and St Thomas' NHS Trust, 4th Floor, Tower Wing, Guy's Hospital, Great Maze Pond, London, UK. 'Academic Department of Rheumatology, Centre for Molecular and Cellular Biology of Inflammation, 1st Floor, New Hunt's House, Guy's Campus, King's College London, Great Maze Pond, London, UK.

Received: 6 August 2018 Accepted: 25 January 2019

Published online: 25 February 2019

\section{References}

1. Rheumatoid arthritis in adults: management NICE guidelines 2009 (updated 2015) CG79. https://www.nice.org.uk/Guidance/CG79. Accessed 1 June 2018

2. Bykerk VP, Akhavan P, Hazlewood GS, et al. Canadian rheumatology association recommendations for pharmacological management of rheumatoid arthritis with traditional and biologic disease-modifying antirheumatic drugs. J Rheumatol. 2012;39:1559-82.

3. Singh JA, Saag KG, Bridges SL, et al. 2015 American College of Rheumatology Guideline for the treatment of rheumatoid arthritis. Arthritis Rheumatol. 2016;68:1-26.

4. Smolen JS, Landewé R, Bijlsma J, et al. EULAR recommendations for the management of rheumatoid arthritis with synthetic and biological disease-modifying antirheumatic drugs: 2016 update. Ann Rheum Dis. 2017;76:960-77.

5. Smolen JS, Breedveld FC, Burmester GR, et al. Treating rheumatoid arthritis to target: 2014 update of the recommendations of an international task force. Ann Rheum Dis. 2016;75:3-15.

6. Wailoo A, Hock ES, Stevenson M, et al. The clinical effectiveness and costeffectiveness of treat-to-target strategies in rheumatoid arthritis: a systematic review and cost-effectiveness analysis. Health Technol Assess. 2017;21:1-258.

7. Silman A, Davies P, Currey HLF, Evans SJW. Is rheumatoid arthritis becoming less severe? J Chronic Dis. 1983;36:891-7.

8. Sokka T, Kautiainen H, Hakkinen A, Hannonen P. Radiographic progression is getting milder in patients with early rheumatoid arthritis. Results of 3 cohorts over 5 years. J Rheumatol. 2004;31:1073-82.

9. Welsing PM, Fransen J, van Riel PL. Is the disease course of rheumatoid arthritis becoming milder? Time trends since 1985 in an inception cohort of early rheumatoid arthritis. Arthritis Rheum. 2005;52:2616-24.

10. Abelson B, Sokka T, Pincus T. Declines in erythrocyte sedimentation rates in patients with rheumatoid arthritis over the second half of the 20th century. J Rheumatol. 2009:36:1596-9.

11. Kievit W, Fransen J, de Waal Malefijt MC, den Broeder AA, van Riel PL. Treatment changes and improved outcomes in RA: an overview of a large inception cohort from 1989 to 2009. Rheumatology. 2013;52:1500-8.

12. Diffin JG, Lunt M, Marshall T, Chipping JR, Symmons DP, Verstappen SM. Has the severity of rheumatoid arthritis at presentation diminished over time? J Rheumatol. 2014;41:1590-9.

13. Pincus T, Sokka T, Kautiainen $H$. Patients seen for standard rheumatoid arthritis care have significantly better articular, radiographic, laboratory, and functional status in 2000 than in 1985. Arthritis Rheum. 2005;52:1009-19.

14. Yamanaka H, Inoue E, Singh G, Tanaka E, Nakajima A, Taniguchi A, Hara M, Tomatsu T, Kamatani N. Improvement of disease activity of rheumatoid arthritis patients from 2000 to 2006 in a large observational cohort study IORRA in Japan. Mod Rheumatol. 2007;17:283-9.

15. Uhlig T, Heiberg T, Mowinckel P, Kvien TK. Rheumatoid arthritis is milder in the new millennium: health status in patients with rheumatoid arthritis 1994-2004. Ann Rheum Dis. 2008:67:1710-5.

16. Aga $A B$, Lie $E$, Uhlig $T$, et al. Time trends in disease activity, response and remission rates in rheumatoid arthritis during the past decade: results from the NOR-DMARD study 2000-2010. Ann Rheum Dis. 2015;74:381-8.

17. Mian AN, Ibrahim F, Scott IC, Bahadur S, Filkova M, Pollard L, Steer S, Kingsley GH, Scott DL, Galloway J. Changing clinical patterns in rheumatoid arthritis management over two decades: sequential observational studies. BMC Musculoskelet Disord. 2016;17:44. 
18. Finckh A, Choi HK, Wolfe F. Progression of radiographic joint damage in different eras: trends towards milder disease in rheumatoid arthritis are attributable to improved treatment. Ann Rheum Dis. 2006;65:1192-7.

19. Fiehn C, Belke-Voss E, Krause D, Wassenberg S, Rau R. Improved radiological outcome of rheumatoid arthritis: the importance of early treatment with methotrexate in the era of biological drugs. Clin Rheumatol. 2013:32:1735-42.

20. Nikiphorou E, Carpenter L, Morris S, et al. Hand and foot surgery rates in rheumatoid arthritis have declined from 1986 to 2011, but large-joint replacement rates remain unchanged: results from two UK inception cohorts. Arthritis Rheumatol. 2014;66:1081-9.

21. Nystad TW, Fenstad AM, Furnes O, Havelin LI, Skredderstuen AK, Fevang BT. Reduction in orthopaedic surgery in patients with rheumatoid arthritis: a Norwegian register-based study. Scand J Rheumatol. 2016;45:1-7.

22. Toledano E, Ortiz AM, Ivorra-Cortes J, Montes N, Beltran A, RodríguezRodriguez L, Carmona L, González-Álvaro I. Are rheumatologists adhering to the concepts window of opportunity and treat-to-target? Earlier and more intense disease-modifying anti-rheumatic drug treatment over time in patients with early arthritis in the PEARL study. Clin Exp Rheumatol. 2018;36:382-8.

23. Firestein GS. The disease formerly known as rheumatoid arthritis. Arthritis Res Ther. 2014;16:114.

24. Nikiphorou E, Norton S, Carpenter L, et al. Secular Changes in Clinical Features at Presentation of Rheumatoid Arthritis: Increase in Comorbidity But Improved Inflammatory States. Arthritis Care Res (Hoboken). 2017;69:21-7.

25. Gullick NJ, Oakley SP, Zain A, Gibson T, Jones T, Mistlin A, Rees JD, Panayi GS, Kirkham BW. Goal-directed therapy for RA in routine practice is associated with improved function in patients with disease duration up to 15 years. Rheumatology. 2012;51:759-61.

26. Scott DL. Biologics-based therapy for the treatment of rheumatoid arthritis Clin Pharmacol Ther. 2012;91:30-43.

27. Smolen JS, Aletaha D, Bijlsma JW, Breedveld FC, Boumpas D, Burmester G, et al. Treating rheumatoid arthritis to target: recommendations of an international task force. Ann Rheum Dis. 2010;69:631-7.

28. van Riel PL, Renskers L. The Disease Activity Score (DAS) and the Disease Activity Score using 28 joint counts (DAS28) in the management of rheumatoid arthritis. Clin Exp Rheumatol. 2016;34(5 Suppl 101):40-4

29. Fries JF, Spitz P, Kraines RG, Holman HR. Measurement of patient outcome in arthritis. Arthritis Rheum. 1980;23:137-45.

30. the EuroQol group. EuroQol--a new facility for the measurement of health-related quality of life. Health Policy. 1990;16:199-208.

31. van der Maas A, Lie E, Christensen $\mathrm{R}$, et al. Construct and criterion validity of several proposed DAS28-based rheumatoid arthritis flare criteria: an OMERACT cohort validation study. Ann Rheum Dis. 2013;72:1800-5.

32. Ma MH, Scott IC, Dahanayake C, Cope AP, Scott DL. Clinical and serological predictors of remission in rheumatoid arthritis are dependent on treatment regimen. J Rheumatol. 2014;41:1298-303.

33. Greenberg JD, Spruill TM, Shan Y, Reed G, Kremer JM, Potter J, Yazici Y, Ogedegbe G, Harrold LR. Racial and ethnic disparities in disease activity in patients with rheumatoid arthritis. Am J Med. 2013;126:1089-98.

34. Rannio T, Asikainen J, Kokko A, Hannonen P, Sokka T. Early remission is a realistic target in a majority of patients with DMARD-naive rheumatoid arthritis. J Rheumatol. 2016;43:699-706.

35. Alemao E, Joo S, Kawabata H, Al MJ, Allison PD, Rutten-van Mölken MP, et al. Effects of achieving target measures in rheumatoid arthritis on functional status, quality of life, and resource utilization: analysis of clinical practice data. Arthritis Care Res. 2016;68:308-17.

36. Radner H, Smolen JS, Aletaha D. Remission in rheumatoid arthritis: benefit over low disease activity in patient-reported outcomes and costs. Arthritis Res Ther. 2014;16:R56.

37. Radner H, Alasti F, Smolen JS, Aletaha D. Physical function continues to improve when clinical remission is sustained in rheumatoid arthritis patients. Arthritis Res Ther. 2015;17:203.

38. Welsing PM, van Gestel AM, Swinkels HL, Kiemeney LA, van Riel PL. The relationship between disease activity, joint destruction, and functional capacity over the course of rheumatoid arthritis. Arthritis Rheum. 2001;44: 2009-17.

39. Kivitz A, Olech E, Borofsky M, Zazueta BM, Navarro-Sarabia F, Radominski SC, Merrill JT, Rowell L, Nasmyth-Miller C, Bao M, Wright S, Pope JE.
Subcutaneous tocilizumab versus placebo in combination with diseasemodifying antirheumatic drugs in patients with rheumatoid arthritis. Arthritis Care Res. 2014;66:1653-61.

40. Smolen J, Landewé RB, Mease P, Brzezicki J, Mason D, Luijtens K, van Vollenhoven RF, Kavanaugh A, Schiff M, Burmester GR, Strand V, Vencovsky J, van der Heijde D. Efficacy and safety of certolizumab pegol plus methotrexate in active rheumatoid arthritis: the RAPID 2 study. A randomised controlled trial. Ann Rheum Dis. 2009;68:797-804.

41. Smolen JS, van Vollenhoven R, Kavanaugh A, Strand V, Vencovsky J, Schiff M, Landewé R, Haraoui B, Arendt C, Mountian I, Carter D, van der Heijde D. Certolizumab pegol plus methotrexate 5-year results from the rheumatoid arthritis prevention of structural damage (RAPID) 2 randomized controlled trial and long-term extension in rheumatoid arthritis patients. Arthritis Res Ther. 2015;17:245

42. Scott IC, Ibrahim F, Lewis CM, Scott DL, Strand V. Impact of intensive treatment and remission on health-related quality of life in early and established rheumatoid arthritis. RMD Open. 2016;2:e000270.

43. Andersson ML, Forslind K, Hafström I. Patients with early rheumatoid arthritis in the 2000s have equal disability and pain despite less disease activity compared with the 1990s: data from the BARFOT study over 8 years. J Rheumatol. 2017:44:723-31.

44. Pollard LC, Kingsley GH, Choy EH, Scott DL. Fibromyalgic rheumatoid arthritis and disease assessment. Rheumatology. 2010;49:924-8.

45. Joharatnam N, McWilliams DF, Wilson D, Wheeler M, Pande I, Walsh DA. A cross-sectional study of pain sensitivity, disease-activity assessment, mental health, and fibromyalgia status in rheumatoid arthritis. Arthritis Res Ther. 2015;17:11.

46. Durán J, Combe B, Niu J, Rincheval N, Gaujoux-Viala C, Felson DT. The effect on treatment response of fibromyalgic symptoms in early rheumatoid arthritis patients: results from the ESPOIR cohort. Rheumatology. 2015;54: 2166-70.

47. Mian AN, Chaabo K, Wajed J, Subesinghe S, Gullick NJ, Kirkham B, Garrood T. Rheumatoid arthritis patients with fibromyalgic clinical features have significantly less synovitis as defined by power Doppler ultrasound. BMC Musculoskelet Disord. 2016;17:404.

48. Matcham F, Ali S, Hotopf M, Chalder T. Psychological correlates of fatigue in rheumatoid arthritis: a systematic review. Clin Psychol Rev. 2015;39:16-29.

49. Rongen-van Dartel SA, Repping-Wuts H, Flendrie M, Bleijenberg G, Metsios GS, van den Hout WB, van den Ende CH, Neuberger G, Reid A, van Riel PL, Fransen J. Effect of aerobic exercise training on fatigue in rheumatoid arthritis: a meta-analysis. Arthritis Care Res (Hoboken). 2015;67:1054-62.

50. Sokka T, Kautiainen H, Pincus T, Toloza S, da Rocha Castelar Pinheiro G, Lazovskis J, et al. disparities in rheumatoid arthritis disease activity according to gross domestic product in 25 countries in the QUEST-RA database. Ann Rheum Dis. 2009;68:1666-72.

51. Treasure $\mathrm{E}$, Scott DL, Katona PM, Toon P. Arthritis in inner city general practices. Br J Gen Pract. 1990;40:81-2.

52. Edwards CJ, Arden NK, Fisher D, Saperia JC, Reading I, Van Staa TP, Cooper $C$. The changing use of disease-modifying anti-rheumatic drugs in individuals with rheumatoid arthritis from the United Kingdom general practice research database. Rheumatology. 2005;44:1394-8.

53. Heimans L, Wevers-de Boer KVC, Ronday HK, Collée G, de Sonnaville PBJ, Grillet BAM, Huizinga TWJ, Allaart CF. Can we prevent rapid radiological progression in patients with early rheumatoid arthritis? Clin Rheumatol. 2015;34:163-6.

\section{Ready to submit your research? Choose BMC and benefit from:}

- fast, convenient online submission

- thorough peer review by experienced researchers in your field

- rapid publication on acceptance

- support for research data, including large and complex data types

- gold Open Access which fosters wider collaboration and increased citations

- maximum visibility for your research: over $100 \mathrm{M}$ website views per year

At BMC, research is always in progress.

Learn more biomedcentral.com/submissions 